\title{
When to eat? The influence of circadian rhythms on metabolic health: are animal studies providing the evidence?
}

\author{
Sofía Moran-Ramos ${ }^{1,2}$, Adrian Baez-Ruiz ${ }^{3}$, Ruud M. Buijs ${ }^{3}$ and Carolina Escobar ${ }^{1 *}$ \\ ${ }^{1}$ Department of Anatomy, Faculty of Medicine, Universidad Nacional Autónoma de México, Mexico City, Mexico \\ ${ }^{2}$ Unidad de Genómica de Poblaciones Aplicada a la Salud, Facultad de Química, Universidad Nacional Autónoma de México \\ (UNAM)-Instituto Nacional de Medicina Genómica (INMEGEN), Mexico City, Mexico \\ ${ }^{3}$ Department of Cell Biology and Physiology, Institute for Biomedical Research, Universidad Nacional Autónoma de México, \\ Mexico City, Mexico
}

\section{Abstract}

As obesity and metabolic diseases rise, there is need to investigate physiological and behavioural aspects associated with their development. Circadian rhythms have a profound influence on metabolic processes, as they prepare the body to optimise energy use and storage. Moreover, food-related signals confer temporal order to organs involved in metabolic regulation. Therefore food intake should be synchronised with the suprachiasmatic nucleus (SCN) to elaborate efficient responses to environmental challenges. Human studies suggest that a loss of synchrony between mealtime and the SCN promotes obesity and metabolic disturbances. Animal research using different paradigms has been performed to characterise the effects of timing of food intake on metabolic profiles. Therefore the purpose of the present review is to critically examine the evidence of animal studies, to provide a state of the art on metabolic findings and to assess whether the paradigms used in rodent models give the evidence to support a 'best time' for food intake. First we analyse and compare the current findings of studies where mealtime has been shifted out of phase from the light-dark cycle. Then, we analyse studies restricting meal times to different moments within the active period. So far animal studies correlate well with human studies, demonstrating that restricting food intake to the active phase limits metabolic disturbances produced by high-energy diets and that eating during the inactive/sleep phase leads to a worse metabolic outcome. Based on the latter we discuss the missing elements and possible mechanisms leading to the metabolic consequences, as these are still lacking.

\section{Key words: Circadian rhythms: Metabolism: Restricted feeding: Obesity: Gut microbiota}

\section{Introduction}

'Breakfast like a king, lunch as a prince, dine as a pauper'; this ancient folk wisdom recently is receiving support from scientific research showing a strong relationship between circadian rhythms and metabolism.

Obesity is a major health problem around the world and most interventions are focused on dietary intake and physical activity. However, there is a growing recognition that factors such as circadian time and dietary behaviour contribute importantly to the metabolic response to food intake and thus to the development of metabolic diseases ${ }^{(1,2)}$. Hereby it is shown that food intake in the rest phase may also contribute to the development of obesity and metabolic abnormalities. Indeed epidemiological data obtained from shift workers show that they have an increased risk for the development of obesity, and metabolic and gastrointestinal diseases ${ }^{(3-5)}$. While other studies show that a specific feeding schedule (such as the ones used in alternate-day fasting studies) can aid weight reduction and improvement in metabolic biomarkers ${ }^{(6,7)}$, certain studies show that in the long term skipping breakfast, independently of energy intake or physical activity, is associated with a greater risk of developing obesity ${ }^{(8)}$. All together these data emphasise the importance of food timing and support that eating at the wrong time of the $24 \mathrm{~h}$ cycle may lead to a disrupted metabolism, ultimately ending in weight gain and metabolic disturbances.

Substantial evidence indicates that rather than obesity per se, metabolic alterations such as chronic low-grade inflammation, ectopic fat deposition and adipocyte dysfunction are critical mediators in obesity-induced diseases ${ }^{(9-12)}$. Recent findings suggest that circadian disruption can favour such processes, thus contributing to the development of metabolic diseases ${ }^{(13,14)}$.

In spite of this general agreement, some animal studies evaluating the effects of food timing on metabolic health report inconclusive and contradicting results, probably due to the use of different protocols. Therefore, the purpose of the present review is to compile and critically discuss current experimental evidence on metabolic outcomes in rodent models where food availability is restricted. Two experimental regimens are considered; in the first part we discuss time-restricted feeding, which involves confining food intake to the day or night. It is

Abbreviations: HF, high-fat: HFr, high-fructose: HS, high-fat-sugar: IPGTT, intraperitoneal glucose tolerance test: SCN, suprachiasmatic nucleus: ZT, Zeitgeber 
worth highlighting that time-restricted feeding studies using one single event of less than $8 \mathrm{~h}$ of food availability along the $24 \mathrm{~h}$ day were excluded, since those paradigms can lead to food entrainment, reset circadian metabolism and induce energy restriction or resemble a fasted day ${ }^{(15)}$, which is not the purpose of the present review. The second part is focused on protocols with feeding schedules restricted to the active phase trying to mimic human meals.

We will also analyse possible mechanisms on how the timing of food intake may contribute to the development of obesity and metabolic abnormalities and discuss possible studies that still need to be done.

\section{Circadian rhythms and metabolism}

The suprachiasmatic nucleus (SCN), situated at the base of the anterior hypothalamus, is the main pacemaker of the circadian system. By receiving input from the retino-hypothalamic tract, the SCN synchronises its neural activity with the light-dark cycle $^{(16)}$; therefore the latter is considered the strongest entrainment signal or Zeitgeber $(\mathrm{ZT})^{(17)}$. The SCN further communicates the external time (day or night) to the body via humoral and neural pathways. Moreover, peripheral signals feed back timing signals to the SCN. This, for example, includes hormone-sensitive brain areas that project to the $\mathrm{SCN}^{(18)}$, as well as sensory feedback, for example, from the autonomic nervous system ${ }^{(16,19)}$. A major function of the circadian machinery is optimising metabolic processes, energy utilisation and storage; therefore a close interaction between circadian and metabolic centres is needed.

The circadian system is involved at many levels in the regulation of energy metabolism. This includes synchronising behaviour such as food intake and locomotor activity with adjustments in physiology (body temperature, heart rate, hormone secretion $)^{(20,21)}$, as well as with cellular and molecular fluctuations such as the uptake and production of metabolites, gene expression and activity of metabolic enzymes ${ }^{(22-24)}$. As a testimony, a substantial amount of hormones and genes in adipose tissue ${ }^{(25,26)}$, muscle ${ }^{(27-29)}$ and liver ${ }^{(30-33)}$ show a circadian rhythm ${ }^{(34-36)}$, depending on the rhythmicity of the SCN. Noteworthy, these processes will influence energy expenditure and thus energy balance, pointing out the metabolic flexibility of different tissues along the day in order to optimise energy use and storage.

In normal physiological conditions, the timing of feeding is driven by the SCN. However, due to the powerful influence of nutrients and food intake on peripheral clocks ${ }^{(37)}$, when food availability is separated from SCN rhythms, the phase of some gene rhythms in several peripheral tissues is modified and thus their metabolic processes ${ }^{(34,38,39)}$. Furthermore the interaction between circadian and metabolic genes ${ }^{(23)}$, and the fact that animals fed a chronic high-fat (HF) diet show disturbances in circadian rhythms, supports a strong influence of nutrients on central and peripheral clocks ${ }^{(17,40-43)}$. Indeed some authors have shown in animal models that a high-energy diet induces alterations in the circadian system contributing to the observed metabolic phenotype ${ }^{(44)}$. Thus it is clear that whether food is ingested during the day or the night will lead to different metabolic consequences.
The importance of endogenous circadian rhythms becomes more evident when they are disrupted. Animal models with genetic defects within the core clock genes or perturbations in circadian oscillation components have been linked to various pathologies including obesity, the metabolic syndrome, cancer, CVD and gastric disorders ${ }^{(45-52)}$. The disadvantage of these animal models is that in some of them, especially the wholebody knock-outs (KO), cellular processes are affected which can ultimately result in the observed pathologies, including metabolic disturbance. Indeed, a recent report showed that induction of $\mathrm{KO}$ after birth does not results in the pathologies of the conventional $\mathrm{KO}$, highlighting that the importance of the developmental period to study the physiological processes ${ }^{(53)}$. Moreover, the non-circadian functions of the core clock genes are disrupted which can have negative impacts on metabolic functions.

Food in the rest phase promotes adiposity, while restriction of a high-fat diet to the active phase prevents metabolic disturbances

As previously mentioned, epidemiological data obtained from shift/night workers show that they have an increased risk for the development of obesity and metabolic abnormalities ${ }^{(54,55)}$. Also other studies demonstrate that timing of food intake, such as night snacking, is associated with higher $\mathrm{BMI}^{(8,56)}$. In an effort to fully characterise the metabolic consequences of mistimed food intake and to propose mechanisms that associate the disrupted circadian system with metabolic disease and obesity, animal studies where food access is restricted only to the day or to the night have been performed. A consistent shift in clock genes expression in organs related to digestion and metabolic function has been reported; however, current information regarding metabolic outcomes after such scheduled meals is still inconclusive. In this section we will present the metabolic findings obtained in studies performed with restricted feeding to day (rest phase) or night (active phase) using either normal or HF diets. Table 1 summarises the diverse alterations in physiology observed under such experimental paradigms.

\section{Body weight and adiposity}

The first evidence that feeding during the wrong time leads to abnormal metabolic outcomes came from a study performed by Arble et $a l .{ }^{(57)}$. They showed in a 6-week study that mice fed a HF diet ( $60 \%$ of energy from fat) restricted to the day gained significantly more weight than their counterparts fed the HF diet during the night (active phase). This difference was also observed in the adiposity index, although only as a tendency. Mice fed during the light period had $8 \%$ more fat deposition than night-fed mice. Interestingly, in this study mice of both groups ate the same amount of energy, and presented similar levels of locomotor activity, indicating a different metabolic management. In view of the communication between the biological clock and metabolism this finding emphasised the importance of an adequate food timing to prevent excessive weight gain. It is important to mention that even though 
Table 1. Summary of day $v$. night restricted feeding protocols and their effects on health and disease in rodents*

\begin{tabular}{|c|c|c|c|c|c|}
\hline Reference & Feeding protocol & Rodent strain & $\begin{array}{l}\text { Length of the } \\
\text { study }\end{array}$ & Type of diet $\dagger$ & Main metabolic outcome \\
\hline Salgado-Delgado et al. ${ }^{(58)}$ & $\begin{array}{l}\text { Ad libitum, } \mathrm{RF} \text { for } 12 \mathrm{~h} \\
\mathrm{DF} \text { or } \mathrm{NF}\end{array}$ & $\begin{array}{l}\text { Wistar rats } \\
\text { (5-6 weeks } \\
\text { old) }\end{array}$ & 4 weeks & Chow & Increased abdominal fat in DF animals $v$. ad libitum and NF animals \\
\hline Salgado-Delgado et al. ${ }^{(71)}$ & $\begin{array}{l}\text { Ad libitum } \mathrm{RF} \text { for } 12 \mathrm{~h} \text {, } \\
\mathrm{DF} v . \mathrm{NF}\end{array}$ & $\begin{array}{l}\text { Wistar rats }(4-5 \\
\text { weeks old) }\end{array}$ & 4 weeks & Chow & $\begin{array}{l}\text { Decreased glucose tolerance (evaluated at ZT4) } \\
\text { Increased liver fat accumulation in DF } v \text {. ad libitum rats }\end{array}$ \\
\hline $\begin{array}{l}\text { Adamovich } \\
\text { et al. }\end{array}$ & $\begin{array}{l}\text { Ad libitum, RF during } \\
\text { night }(12 \mathrm{~h})\end{array}$ & Miceł & 2 weeks & Chow & Decreased liver fat in NF $v$. ad libitum mice \\
\hline Gil-Lozano et al. $^{(75)}$ & $\mathrm{RF}$ for $12 \mathrm{~h} \mathrm{DF} v . \mathrm{NF}$ & $\begin{array}{l}\text { Wistar rats } \\
\quad(300-350 \mathrm{~g})\end{array}$ & 3 weeks & Chow & Decreased oral glucose tolerance in DF $v$. NF at ZT22 \\
\hline Shamsi et al. ${ }^{(65)}$ & $\begin{array}{l}\text { RF during the day or } \\
\text { night with } 8 \mathrm{~h} \text { light-16 } \mathrm{h} \\
\text { dark or } 16 \mathrm{~h} \text { light- } 8 \mathrm{~h} \\
\text { dark photoperiods }\end{array}$ & $\begin{array}{l}\text { C57BL/6 mice } \\
\text { (4 weeks old })\end{array}$ & $28 d$ & Chow & $\begin{array}{l}\text { Improved insulin sensitivity in DF mice under a } 16 \mathrm{~h} \text { light-8 } \mathrm{h} \\
\text { dark cycle }\end{array}$ \\
\hline Arble et al. ${ }^{(57)}$ & $\mathrm{RF}$ for $12 \mathrm{~h} \mathrm{DF} v . \mathrm{NF}$ & $\begin{array}{l}\text { C57BL/6J mice } \\
\text { (9 weeks old })\end{array}$ & 6 weeks & HF diet $(60 \%) \S$ & Higher weight gain and adiposity in DF rats \\
\hline Jang et al. ${ }^{(64)}$ & $\begin{array}{l}\mathrm{RF} \text { for } 12 \mathrm{~h} \text { day } v \text {. pair-fed } \\
\text { in the night }\end{array}$ & $\begin{array}{l}\text { C57BL/6N mice } \\
\text { (4 weeks old) }\end{array}$ & 4 weeks & $\begin{array}{l}\text { Chow and HF diet } \\
(60 \%) \S\end{array}$ & No changes in body weight \\
\hline Hatori et al. ${ }^{(40)}$ & $\begin{array}{l}\text { Ad libitum v. RF during } \\
\text { the night }(8 \mathrm{~h})\end{array}$ & $\begin{array}{l}\text { C57BL/6J mice } \\
\text { (8 weeks old })\end{array}$ & 3 months & $\begin{array}{l}\text { Chow and HF diet } \\
(61 \%) \S\end{array}$ & $\begin{array}{l}\text { NF-HF mice showed improvements in adiposity, liver steatosis, } \\
\text { glucose tolerance during the inactive phase, markers of } \\
\text { inflammation in WAT and increased energy expenditure } v \text {. } \\
\text { ad libitum mice }\end{array}$ \\
\hline Chaix et al. ${ }^{(43)}$ & $\begin{array}{l}\text { Ad libitum v. RF during } \\
\text { the night }(9 \text { or } 12 \mathrm{~h})\end{array}$ & $\begin{array}{l}\text { C57BL/6J mice } \\
\text { (12 weeks old) }\end{array}$ & $11-12$ weeks & $\begin{array}{l}\text { Chow, } \mathrm{HFr}(88 \%), \mathrm{HS} \\
(55 \% \text { sucrose, } 30 \% \\
\text { fat) and HF diets } \\
(61 \%) \S\end{array}$ & $\begin{array}{l}\text { RF mice with HFr, HS or HF diet showed improvements in body fat, } \\
\text { glucose tolerance, liver steatosis, serum TAG and total cholestero } \\
\text { levels } v \text {. ad libitum mice }\end{array}$ \\
\hline Zarrinpar et al. ${ }^{(60)}$ & $\begin{array}{l}\text { Ad libitum } v \text {. RF during } \\
\text { the night }(8 \mathrm{~h})\end{array}$ & $\begin{array}{l}\text { C57BL/6J mice } \\
\text { (12 weeks old })\end{array}$ & 8 weeks & $\begin{array}{l}\text { Chow and HF diet } \\
(61 \%) \S\end{array}$ & $\begin{array}{l}\text { RF mice with HF diet showed less weight gain, improved glucose } \\
\text { tolerance and partially restored bacterial diurnal fluctuations }\end{array}$ \\
\hline Reznick et al. ${ }^{(59)}$ & $\begin{array}{l}\text { Ad libitum and } \mathrm{RF} \text { for } \\
12 \mathrm{~h} \text { DF } v . \mathrm{NF}\end{array}$ & $\begin{array}{l}\text { Wistar rats }(200- \\
250 \mathrm{~g})\end{array}$ & 3 weeks & $\begin{array}{l}\text { Chow and HF diet } \\
(60 \%) \S\end{array}$ & $\begin{array}{l}\text { Reduced energy expenditure in DF } v \text {. ad libitum rats. Increased } \\
\text { epididymal fat pads in DF } v \text {. NF animals }\end{array}$ \\
\hline Tsai et al. ${ }^{(66)}$ & $\begin{array}{l}\text { Ad libitum and } 12 \mathrm{~h} \text { RF } \\
\text { day } v \text {. night }\end{array}$ & $\begin{array}{l}\mathrm{FVB} / \mathrm{N} \text { mice } \\
\quad(12 \text { weeks old })\end{array}$ & $12-16$ weeks & $\begin{array}{l}\text { Control }(10 \% \text { energy } \\
\text { from fat) } \| \text { and } \mathrm{HF} \\
\text { diet }(45 \%) \S\end{array}$ & $\begin{array}{l}\text { Improved adaptation in cardiac function in } \\
\text { HF-NF } v \text {. HF ad libitum mice }\end{array}$ \\
\hline Morris et al. ${ }^{(61)}$ & $\begin{array}{l}\text { Ad libitum chow }+ \\
\text { fructose solution } \\
\text { day } v \text {. night }\end{array}$ & $\begin{array}{l}\text { C57BL mice } \\
\text { (about } \\
8 \text { weeks old) }\end{array}$ & 6 weeks & $\begin{array}{l}\text { Chow }+10 \% \text { fructose } \\
\text { solution }\end{array}$ & $\begin{array}{l}\text { Greater adiposity and higher fasting serum insulin levels (ZT2), } \\
\text { in mice with fructose during day } v \text {. fructose at night }\end{array}$ \\
\hline
\end{tabular}

RF, restricted feeding; DF, day fed; NF, night fed; ZT, Zeitgeber; HF, high-fat; WAT, white adipose tissue; HFr, high-fructose; HS, high-fat-sugar. * All the summarised studies were performed in male rodents.

† Chow refers to the standard food given in the vivarium.

¥ No information on strain or age.

$\S$ Percentage of HF diet reflects energy from fat.

\| Control diet is a purified diet with matched amount of fibre, proteins, vitamins and minerals. 
Arble et al. ${ }^{(57)}$ reported big differences in body weight, other studies using similar protocols have not observed differences of the same magnitude and some have found only tendencies. Salgado-Delgado et al. ${ }^{(58)}$ performed a 4 -week study in rats fed with a chow diet during the light (inactive phase in rodents) or during the dark (active) phase. They showed that despite the same levels of energy intake, and locomotor activity, day-fed rats gained more weight and accumulated bigger abdominal fat pads than rats fed during the night or ad libitum. Recently, Reznick et $a l .{ }^{(59)}$ performed a 3-week protocol with $\mathrm{HF}$ and chow diets, and compared day-fed $v$. ad libitum rats. In this study, despite less energy intake in day-fed animals, their weight gain and epididymal adiposity were not different from the ad libitum rats. To support this finding they compared day-fed rats with rats pair-fed during the night. In this experiment they confirmed an increase in epididymal fat pads in the day-fed group compared with the night-fed animals. An interesting finding was that day-fed animals, either chow or HF, had significantly higher levels of plasma adiponectin compared with ad libitum rats. Since adiponectin is an anti-inflammatory adipokine it would be worthwhile to further investigate if indeed higher levels are maintained in the long term and if it has any implications for the inflammatory processes on adipose tissue or the liver.

The previous studies show the negative impact of feeding during the inactive phase on body weight and adiposity. In contrast, restriction of food intake to the active phase seems to have beneficial effects. Hatori et al. ${ }^{(40)}$ performed a timerestricted feeding protocol providing access to food only during the night phase. Mice were fed a normal chow or a HF diet (61\% energy from fat) either ad libitum or for $8 \mathrm{~h}$ during the night (ZT13-ZT21) for 3 months. In spite of similar cumulative food intake of HF night-fed and ad libitum HF mice, mice fed during the night showed significant improvement in adiposity. These results were replicated in two other studies by the same group where older mice (12 weeks old) fed for 8-12 weeks on a HF, high-fructose ( $\mathrm{HFr}$ ) or high-fat-sugar (HS) diet also showed less weight gain and adiposity when compared with ad libitum mice ${ }^{(43,60)}$. As mentioned before, obesity-associated metabolic abnormalities do not result just from higher adiposity, but rather from the abnormal functioning of adipocytes and the low-grade inflammation ${ }^{(12)}$. In this line, Hatori et al. ${ }^{(40)}$ also observed that night HF feeding led to decreased adipocyte size and improvements in markers of white adipose tissue inflammation, extending the benefits of eating only during the active period. Unfortunately in this study a group of mice fed during the day (inactive phase) was omitted; thus the effects of day $v$. night eating could not be compared.

Apart from HF food, Morris et al. ${ }^{(61)}$ investigated the effects of fructose intake during day or night for 6 weeks. High fructose intake as part of the typical Western diet has been associated in rodents with the development of fatty liver and other cardiometabolic abnormalities ${ }^{(62,63)}$. In this study, mice had ad libitum access to chow and were provided with a $10 \%$ fructose solution during the light period (12h) or during the dark phase $(12 \mathrm{~h})$. Although this was not a fully restricted feeding protocol, because chow was provided ad libitum, it was observed that after 6 weeks of fructose intake during the night, mice had apparently no significant metabolic effects compared with the control group. In contrast and despite no differences in energy intake, fructose ingestion during the day induced increased body fat compared with fructose during the night, albeit no changes in body-weight gain, suggesting there was a corresponding decrease in lean body mass. Further assessment of adipocyte profile confirmed higher serum leptin levels and larger adipocytes in mice with fructose intake during the day, when compared with the night group.

Jang et al. ${ }^{(64)}$ provided mice with the same amount of food during the day or night for 4 weeks; they pair-fed the night group against the energy intake of day-fed mice. They did not observe significant body-weight differences between day-fed mice and the pair-fed night group with either chow or the HF diet. They concluded that the observed changes in peripheral circadian clock gene expression as well as in glucose and lipid metabolism genes may not be a key factor influencing body weight. Considering that similar protocols have found differences in adiposity and physiology independent of body-weight gain $^{(59)}$, the limitation of this study is that adiposity was not assessed. In addition, the lack of differences could be attributed to other influencing factors, such as gut microbiota composition and physiological differences between colonies, among others.

All the studies previously mentioned use the conventional $12 \mathrm{~h}$ light-12 h dark cycle. Recently Shamsi et al ${ }^{(65)}$ performed a restricted feeding protocol in mice exposed to either long or short days ( $16 \mathrm{~h}$ light- $8 \mathrm{~h}$ dark or $8 \mathrm{~h}$ light $-16 \mathrm{~h}$ dark, respectively) trying to resemble photoperiods corresponding to either the summer or winter. Interestingly, after 6 weeks under their corresponding photoperiod, they did not find any difference in body weight or food intake between the ad libitum, the night- or day-fed groups. In the groups on the winter schedule ( $8 \mathrm{~h}$ light-16 h dark), mice fed during the light period showed reduced adiposity, compared with ad libitum and night-fed mice, even though the three groups had the same average food intake. This effect may be due to metabolic adjustments in response to a shorter time of food availability or to winter conditions.

\section{Energy expenditure}

In most of the aforementioned studies, the differences in body weight between day and night feeding were associated with no differences in food intake. In an effort to understand the nature of these differential effects, some authors have assessed energy expenditure, or substrates used for energy. Hatori et al. ${ }^{(40)}$, using a regular or a $\mathrm{HF}$ diet, found that mice restricted to food access for the first $8 \mathrm{~h}$ of the night significantly increased their energy expenditure compared with the ad libitum groups. This probably explains the lower adiposity observed in night-fed $v$. ad libitum mice. Surprisingly, and in contradiction to Hatori's finding, Tsai et al. ${ }^{(66)}$ observed that night-fed mice decreased their average daily energy expenditure when compared with ad libitum mice and this was independent of the diet consumed (control or HF diet). On the other hand, Reznick et al ${ }^{(59)}$ found reduced energy expenditure in the day-fed rats compared with night-fed, and ad libitum rats, with no apparent difference between night-fed and ad libitum animals. An interesting point 
in the latter study is that the biggest decrease in energy expenditure in day-fed rats was observed during the dark phase.

These different findings may be explained by the experimental conditions such as age and strain of rodents, length of study and type of diet, among others. As observed in Table 1, one of the studies used rats and the other two used mice but of different strains and even different ages. It has been shown that the genetic background or housing conditions can make an impact on the development of a certain phenotype ${ }^{(67)}$. In addition, only Tsai et al. ${ }^{(66)}$ used the recommended control diet, as regular chow supplied in the vivarium can vary in composition, contributing to the lack of reproducibility. Given that energy expenditure has a key role in energy balance and obesity it is clear that more long-term studies ( $>10$ weeks) with similar protocols are needed to fully evaluate the impact of day $v$. night feeding and to make the results comparable with each other.

\section{Core body temperature}

Energy expenditure is a potential contributor to the differences in adiposity observed between day- and night-fed animals and is importantly influenced by core body temperature. Recent studies demonstrate that brown adipose tissue is a main thermogenic organ, responsible for generating heat and thus maintaining body temperature, with an important role in the development of obesity ${ }^{(68)}$. The latter highlights the importance of measuring core body temperature in metabolic studies. Some of the studies summarised in Table 1, while evaluating metabolic outcomes, also evaluated core body temperature. Salgado-Delgado et $a l .{ }^{(58)}$ showed that in day-fed rats for 4 weeks, the acrophase of core body temperature was shifted to the light/dark transition, rather than in the middle of the night, as observed in ad libitum and night-fed rats. Consequently, animals lost their day/night rhythmicity and the mean body temperature was similar between day and night. Interestingly, in a similar study by Satoh et al. ${ }^{(69)}$, restriction of food intake to the day induced torpor-like symptoms during the late night, the animals entering into an energy-saving mode by lowering their body temperature during this phase. Clearly more studies are needed to strengthen the latter results for core body temperature. However, considering that the daily variation in core body temperature is regulated by the SCN and also by food intake, these results show how misalignment between both processes can make an impact on metabolism and could result in higher adiposity.

\section{Ectopic fat accumulation}

One of the metabolic disturbances commonly observed in obesity is the ectopic accumulation of fat in non-adipose tissues, including the pancreas, heart, liver, kidney and blood vessel wall. This process has deleterious consequences, termed lipotoxicity, and it is seen as the cause for hepatic and peripheral insulin resistance ${ }^{(70)}$. Salgado-Delgado et al. ${ }^{(71)}$ observed in a 4-week study a greater fat accumulation in the liver of rats fed a chow diet during the day, when compared with rats fed ad libitum or during the night. This is of special interest as there were no previous reports of fat accumulation in the liver under a normal-fat diet. However, with 3 weeks of day-feeding Reznick et $a l .{ }^{(59)}$ did not observe such differences in chowor in HF-fed rats, when compared with their corresponding ad libitum groups. These contrasting results suggest that liver fat accumulation may require more time to develop. Reznick's study also found that the diurnal peak in liver TAG, which appeared between ZT6 and ZT9 in ad libitum rats, disappeared in day-fed rats. They additionally measured muscle TAG accumulation with no differences between the different restricted feeding groups.

The reports with night feeding, especially under a HF diet, are more consistent and show that when food is restricted to the night this substantially prevents liver TAG accumulation. Indeed, restriction of different Western-type diets (HF, HFr or HS) to the night-phase improved significantly liver steatosis and markers of hepatic injury compared with HF ad libitum ${ }^{(40,43,60)}$. In an effort to elucidate the molecular mechanism behind this change under a HF diet, Hatori et $a l .{ }^{(40)}$ performed gene expression and metabolome analysis. Their main findings were a more robust rhythm in metabolic genes and significant changes in the liver metabolome. Specifically, they observed an increase in ketone bodies (as a marker of fatty acid oxidation) and hepatic bile acids in the night-fed groups. They suggest that bile acid spillover from the liver correlates with an increased expression of uncoupling proteins in brown adipose tissue and therefore with the increase in energy expenditure observed in night-fed mice.

Adamovich et $a l .{ }^{(72)}$ also evaluated the effect of timed feeding on hepatic TAG in mice. In an elegant study they performed lipidomics analysis of the liver by MS. After only 2 weeks of restricted feeding with a chow diet, mice fed during the night, in spite of an unchanged energy intake, had almost a $50 \%$ decrease in total hepatic TAG, compared with ad libitum mice. Although they quantified the different TAG forms in the liver, this difference was not due to a specific one and rather evident in every single TAG form.

In conclusion; restricting food to the active phase (night in rodents) has a clear positive impact on hepatic TAG either on a regular or on a HF diet.

\section{Glucose homeostasis and insulin sensitivity}

There is a circadian rhythm in insulin action and glucose homeostasis, the former mainly regulated by the $\mathrm{SCN}^{(73)}$. Since insulin sensitivity is the lowest during the inactivity phase $\mathrm{e}^{(74)}$ and insulin resistance is a common metabolic disturbance associated with obesity, restricted feeding studies have evaluated the impact of such experimental paradigms on glucose tolerance. Salgado-Delgado et al. ${ }^{(71)}$ showed that after 4 weeks of food during the day, and an overnight fast, rats showed higher glucose peaks during an intraperitoneal glucose tolerance test (IPGTT) evaluated at ZT4, when compared with night-fed and ad libitum rats. One of the disadvantages of the IPGTT is that this administration route does not stimulate the intestinal secretion of incretins (glucagon-like peptide-1 (GLP-1) and glucagon-dependent insulinotropic peptide (GIP)), which 
are responsible for about $50 \%$ of the insulin secretion after a meal. Therefore, even though this procedure gives information about insulin sensitivity it is impossible to see disturbances in gut-related hormones and does not necessary resemble a meal response. To dissect the role of incretins, Gil-Lozano et al. ${ }^{(75)}$ in a 3 -week study with day or night feeding evaluated changes in GLP-1 secretion. They performed an oral glucose tolerance test (OGTT) at two moments of the day (ZT10 and ZT22) and with $4 \mathrm{~h}$ of prior fasting. They found higher glucose peaks during the OGTT in day-fed rats when compared with night-fed rats, but only at ZT22. An important finding was that day-fed rats showed higher glucose peaks in spite of higher GLP-1 and no changes in insulin secretion, compared with night-fed rats at the same time point. This may imply that after a 3-week period, the differences in glucose peaks between day- and night-fed animals arise from changes in insulin sensitivity, rather than from impaired hormone secretion. Interestingly, the pancreas of day-fed rats seemed to develop some resistance to the incretin effect of GLP-1.

In the study by Hatori et al. ${ }^{(40)}$, an IPGTT was performed during the inactive phase (no specific information on $\mathrm{ZT}$ ). In contrast to ad libitum HF mice, night-HF restricted mice did not display glucose intolerance and instead showed similar glucose and insulin levels to chow-fed mice. The beneficial effect of time-restricted feeding during the active phase when compared with ad libitum on glucose tolerance was also observed in a replicate study ${ }^{(43)}$. This time the IPGTT was evaluated during the active phase (ZT14), and the effect was observed for the three experimental diets (HF, HFr and HS).

In the study by Morris et al. ${ }^{(61)}$, fructose ingestion during the day showed no impact on glucose levels during an IPGTT (no information on the test timing); however, it did induced higher fasting serum insulin levels (evaluated at ZT2) when compared with the night fructose ingestion. The latter further supports the hypothesis of impaired insulin sensitivity under rest-phase feeding. Finally, Shamsi et al. ${ }^{(65)}$ found, in a long-day protocol (summer), that after an overnight fast, day-fed mice had better insulin sensitivity than ad libitum and night-fed mice. However, it must be noted that both the IPGTT and insulin sensitivity test were performed $2 \mathrm{~h}$ after the lights were turned on. Since dayfed animals were in their feeding phase, these results may indicate that after 6 weeks there is some adaptation, while in night-fed animals the optimal response to glucose is shifted to the opposite part of the day.

Existing findings indicate that there is still no consistent effect of timed feeding on glucose tolerance, largely because the glucose tolerance evaluation method and timing should be standardised in order to have comparable results. Glucose tolerance and insulin sensitivity change across the day and night ${ }^{(74)}$; therefore, as Gil-Lozano et al. ${ }^{(75)} \mathrm{did}$, it is convenient to perform the glucose tolerance tests at specific ZT during the light and during the dark phase and to evaluate whether both conditions follow the same tendency or if the observed differences are only a result of adaptation. In addition in order to not neglect the effect of incretins and make the results more comparable with humans, we suggest the use of OGTT instead of IPGTT.

\section{Other cardiometabolic disturbances}

Disturbed circadian rhythms have been associated with CVD; thus some protocols have evaluated parameters associated with cardiovascular function. In line with the previous benefits observed by night restricted feeding in rodents, Tsai et al. ${ }^{(66)}$ observed that mice with a nocturnal feeding schedule achieved an adequate myocardial adaptation under a HF diet preserving contractile function. Specifically, they observed that with this type of diet, ad libitum HF mice showed an approximately $33 \%$ decrease in cardiac power, when assessed ex vivo ${ }^{(76)}$. In contrast, HF night-fed mice had comparable cardiac power as night-fed mice on a regular diet. An interesting point is that this finding was in spite of similar accumulation of TAG in the heart compared with HF ad libitum mice. Surprisingly, under high workload conditions, hearts of HF night-fed mice exhibited even greater ex vivo cardiac power, relative to control mice. Cardiac function shows circadian behaviour ${ }^{(47,77)}$; thus the limitation of the latter findings is that since the authors do not report the time at which the cardiac function was evaluated it is hard to conclude whether this phenomenon is related to any food-derived adaptation. Night-fed mice on a HF diet displayed lower serum cholesterol levels ${ }^{(40)}$.

\section{Conclusion}

Consumption of a HF diet has been associated with disturbances in circadian rhythms ${ }^{(44)}$. Indeed it has been suggested that the metabolic abnormalities observed under such diets result not only from the type of diet, but also from disturbances in components of circadian rhythms ${ }^{(40)}$.

Studies here described show that eating only during the night (active phase for rodents) limits the adiposity and metabolic disturbances such as hepatic steatosis produced by high-energy diets. The different magnitude of the effects, as we will revise in the next section, could be due to the timing of food intake within the active phase.

Most studies show that eating during the inactive phase (light) leads to greater adiposity, which could be related to decreased energy expenditure. The development of fatty liver with day feeding seems to be clear in long-term studies ( $>4$ weeks duration), whereas the development of metabolic abnormalities such as glucose intolerance or hyperinsulinaemia, either on normal-fat or HF diets, is still inconclusive. The lack of consistency in these findings may be attributed to the different protocols used, hours of feeding, length of the study, and rodent strain used, among others. Some studies use chow (the food provided in the vivarium) as the control diet, while others use purified diets. Chow is not necessarily a good control since its composition is variable and the metabolic outcome of purified diets $v$. chow is different ${ }^{(78)}$. Most of the protocols have a relative short duration (3-6 weeks); therefore more long-term studies ( $>12$ weeks) are needed to evaluate whether the metabolic abnormalities result from a lack of adaptation. It is worth highlighting that studies with short duration of food access (4-5 h) either during the day or night resemble a fasted day, which in the long term does not necessarily reflect normal feeding behaviour in humans (where food is available 
Table 2. Summary of restricted feeding protocols within the active period and their effects on health and disease in rodents

\begin{tabular}{|c|c|c|c|c|c|}
\hline Reference & Feeding protocol & Rodent strain & $\begin{array}{l}\text { Length of } \\
\text { study }\end{array}$ & Type of diet & Main metabolic outcome \\
\hline Bray et al. ${ }^{(80)}$ & $\begin{array}{l}\text { Morning (early night) } v \text {. evening } \\
\text { (late night) HF meal }\end{array}$ & $\begin{array}{l}\text { Mice, FVB/N } \\
\text { background } \\
\text { (no age } \\
\text { information) }\end{array}$ & 12 weeks & HF diet (45\%) & $\begin{array}{l}\text { Higher adiposity, hyperinsulinaemia and } \\
\text { insulin resistance (evaluated at ZT12) in } \\
\text { evening } v \text {. morning eaters }\end{array}$ \\
\hline Wu et al. ${ }^{(77)}$ & $\begin{array}{l}\text { Breakfast or dinner skipping on a } \\
\text { three meal/d protocol }\end{array}$ & Wistar rats & 4 weeks & NS & $\begin{array}{l}\text { Despite same food intake, rats with no } \\
\text { dinner had lower body weight and } \\
\text { epididymal fat }\end{array}$ \\
\hline Fuse et al. ${ }^{(82)}$ & $\begin{array}{l}\text { Ad libitum } v \text {. one meal/d or two } \\
\text { meals/d }\end{array}$ & $\begin{array}{l}\text { ICR mice } \\
\text { (6 weeks old })\end{array}$ & 8 weeks & HF diet (40\%) & $\begin{array}{l}\text { Higher body-weight gain, } \\
\text { hyperinsulinaemia, hyperleptinaemia with } \\
\text { one meal/d } v \text {. two meals/d }\end{array}$ \\
\hline $\begin{array}{l}\text { Sasaki } \\
\quad \text { et al. }\end{array}$ & $\begin{array}{l}\text { Early night } v \text {. evening late night } \\
\text { HF meal }\end{array}$ & ICR mice & 4 weeks & HF diet $(45 \%)$ & $\begin{array}{l}\text { Lower body weight and preferential use of } \\
\text { fat in morning } v \text {. evening eaters and ad } \\
\text { libitum }\end{array}$ \\
\hline
\end{tabular}

HF, high-fat; ZT, Zeitgeber; NS, not stated.

throughout the day or night). Therefore such restricted feeding models are not adequate to study the contribution of food timing to obesity in humans. Finally, since glucose tolerance fluctuates along the $24 \mathrm{~h}$ period, its evaluation needs to be standardised to certain time points during the day and night to discriminate adaptation from real abnormalities.

\section{Best timing for food intake: an early meal has a better} metabolic outcome than a late meal - breakfast $v$. dinner

The last section shows that in animal studies there is a clear metabolic advantage of confining food intake to the active period. On the other hand, human studies demonstrate that timing of food intake within the active phase can differentially influence the rate of weight-loss regimens ${ }^{(2,79)}$, and that skipping breakfast is associated with higher $\mathrm{BMI}^{(8,56)}$. In order to characterise the metabolic effects of food intake within the active phase and beyond, circadian rodent studies were done with different meal times circumscribed to the active phase. Table 2 summarises the diverse physiological effects observed under such experimental paradigms. As previously mentioned, rodents are nocturnal animals and their night corresponds to our day. For comparative purposes with human meals, a meal during the first hours of the active phase in rodents will be called breakfast, while the last meal in this phase will be called supper.

\section{Body weight and adiposity}

Bray et $a l .{ }^{(80)}$ performed an experiment where they provided mice a HF diet for $4 \mathrm{~h}$ during the early (ZT12-ZT16) 'breakfast' or late night (ZT20-ZT24) 'dinner', and gave a control diet (normal fat content) for the alternate $4 \mathrm{~h}$. Consequently, animals were food deprived from ZT16 to ZT20, having a total feeding duration of $8 \mathrm{~h}$. Despite identical daily total energy intake, mice with a HF breakfast exhibited significantly lower body weight and lower adiposity, relative to mice with a HF supper. Unfortunately, they did not compare their groups with an ad libitum control or ad libitum HF diet and therefore it is difficult to evaluate the magnitude of the metabolic changes induced by the different protocols. Supporting these results, Sasaki et al. ${ }^{(81)}$ performed a similar protocol with a HF diet. They provided mice with $4 \mathrm{~h}$ of feeding during the early (ZT12-ZT16) or late active phase (ZT20-ZT24), to resemble human meals (eating breakfast or supper). Despite lower food intake, supper eaters had a similar weight gain compared with ad libitum groups. Breakfast eaters had comparable food intake to supper eaters but displayed significantly lower body weight. Interestingly, the difference in body fat did not follow the same pattern; only breakfast eaters had lower adiposity than ad libitum mice, probably because of their lower food intake. While the soleus muscle weight in breakfast eaters was significantly higher relative to ad libitum and supper eaters, no difference between groups was observed in the gastrocnemius weight. Since soleus is composed mainly of oxidative fibres, this result may suggest that under a HF diet, breakfast eating has more impact either in the muscle lipid accumulation or muscle growth.

In the same line, another study evaluated the metabolic effects of meal timing within the active period in young Wistar rats ${ }^{(77)}$. In this study, a three-meal protocol was used as the control to mimic human habits. In the experimental groups either the first meal (breakfast) or the last meal (supper) was suppressed. The main finding was that the group that skipped the supper gained significantly less body weight and less epididymal fat, in spite of lower mean daily locomotor activity. An interesting finding is that in contrast to skipping breakfast, missing supper had almost no impact on the peripheral circadian rhythms. Based on these findings, the authors suggest that the time of the first meal rather than the last probably exerts the major effect on the phase of clock and metabolic genes.

Fuse $e t a l{ }^{(82)}$ compared in mice the effect of one meal (big breakfast) $v$. two meals per d (breakfast and small supper) or free feeding on metabolic health. They fed the three groups a HF diet ( $40 \%$ energy from fat). Groups for one and two meals received $80 \%$ of the food of the free-feeding group. Restriction of the HF diet resulted in significantly lower weight gain and lower total adiposity compared with ad libitum mice. Interestingly, in spite of the same energy intake between one and two meals groups, mice on the two-meal protocol had significantly lower 
body weight and visceral fat compared with the one-meal group. This result stresses that short intervals of food intake or long intervals of fasting do not necessarily improve metabolic outcomes and highlights the importance of also assessing meal frequency.

\section{Energy expenditure}

Timing of food intake within the active period seems not to be crucial for energy expenditure, but has an important effect on the preference of the substrate used. In the study by Bray et $a l .{ }^{(80)}$ energy expenditure was unchanged between breakfast (early active phase) or supper (late active phase) eaters. However, the capacity to switch fuel consumption (carbohydrates $v$. fat) according to availability, also termed metabolic plasticity ${ }^{(83)}$, appears to be lost in the evening HF-fed mice. RER in the latter group remained close to a value of 1 throughout the entire awake/dark phase, despite a period of fasting, and during the HF diet consumption (which in other studies there was a decrease in RER). The latter may imply that there is no metabolic plasticity in mice with a HF diet supper, and therefore the main substrates used are carbohydrates. Sasaki et al. ${ }^{(81)}$ obtained similar results, i.e. no change in overall energy expenditure; however, the mean RER, during the inactive phase, was significantly lower in breakfast $v$. supper eaters, while no difference was observed during the active phase. These experiments consistently indicate that eating early in the active phase (breakfast) allows adaptation to a HF diet, thus using fat for energy production. In contrast, mice eating a HF diet during the late active phase (supper) fail to adapt and mainly use carbohydrates as fuel. The latter can make a deep impact on fat accumulation in the adipose or non-adipose tissues, leading to lipotoxicity and metabolic alterations. Furthermore, it supports that breakfast, as a meal early in the active phase, sets the rhythm of metabolic functions and that it needs to be aligned with SCN signals.

\section{Glucose homeostasis and insulin sensitivity}

The impact of timing of food intake within the active period on glucose homeostasis is still scarce. In the study by Bray et al. ${ }^{(80)}$ an IPGTT was performed at ZT12, the beginning of the active phase, to enforce the $12 \mathrm{~h}$ fasting period and to resemble human studies. The HF diet as breakfast resulted in increased glucose tolerance compared with HF feeding in the evening where animals displayed insulin resistance and hyperinsulinaemia. Fuse et al. ${ }^{(82)}$ showed that the two-meal and one-meal protocol on a HF diet abolished $24 \mathrm{~h}$ fasting insulin rhythms when compared with the ad libitum group; unfortunately, glucose levels were not measured. Although not significant, the two-meal $v$. one-meal group showed lower mean fasting serum insulin levels. From the studies above it seems inappropriate to draw any conclusions; clearly more studies are still warranted.

\section{Conclusion}

The metabolic effects of the timing of food intake within the active phase seem to agree in their main results. It appears that a 'better' timing for food intake is early in the active phase, in order to limit the impact of HF diets, such as the typical Western diet. While there is no apparent change in energy expenditure, a specific temporal order in the daily meal pattern appears to influence metabolic plasticity and therefore important to either accumulate or mobilise fat from adipose tissue. Food received during the first hours of the active phase in rodents programmes the body for a specific use of fuel. In contrast, food intake and particularly high-energy meals during the last part of the active phase seem to have a deleterious impact on the development of adiposity and on weight gain. While Bray et al. ${ }^{(80)}$ observed a worse metabolic outcome by eating a HF supper (late activephase meal) $v$. a HF breakfast (early active-phase meal), more evidence on the impact on metabolic disturbances beyond adiposity is still lacking.

\section{Metabolic effects of food timing: possible mechanisms}

Based on the current findings, in the following paragraphs we discuss possible mechanisms contributing to the observed phenotypes under restricted feeding regimens.

\section{Suppressed thermogenesis, a thrifty phenotype}

In the context of obesity, thermogenesis produced by brown adipose tissue has drawn significant attention, due to its influence on insulin sensitivity ${ }^{(84)}$ and energy expenditure ${ }^{(85)}$. It was suggested that a suppressed thermogenesis induces a thrifty phenotype, predisposing to insulin resistance and obesity ${ }^{(86)}$. In contrast, increasing the thermogenic activity of brown adipose tissue could represent a novel method to combat obesity $^{(87)}$. In rodents, food during the rest phase modifies the daily rhythm in body temperature and induces a significant decrease in body temperature during the active phase ${ }^{(69,88)}$. Our own unpublished observations support this, as rats fed for $12 \mathrm{~h}$ during the rest phase for 9 weeks show a decrease in the amplitude of daily body temperature rhythms, characterised by a decreased body temperature during their active phase when compared with controls. In parallel Reznick et al. ${ }^{(59)}$ found that food during the rest phase, either chow or a HF diet, induced a decrease in energy expenditure when compared with ad libitum and rats fed in the active phase; unfortunately they did not evaluate body temperature ${ }^{(59)}$. More systematic studies evaluating core body temperature, energy expenditure and insulin sensitivity at the same time are needed to strengthen the latter results. Nonetheless, we can propose that the difference in body temperature between rats fed in the rest phase and ad libitum rats results from alterations in brown adipose tissue activation and could partly account for the observed changes in energy expenditure, and consequently in adiposity. An interesting point is that in models of catch-up growth, a key hallmark is the suppressed thermogenesis, accompanied by hyperinsulinaemia, insulin resistance in skeletal muscle and insulin hyper-responsiveness in adipose tissue ${ }^{(89)}$. While in rest-phase feeding studies there is some evidence of insulin resistance for glucose uptake, it will be interesting to also evaluate if the adipose tissue presents such hyper-responsiveness, and whether this contributes to the increased adiposity. 


\section{Uncoordinated metabolic responses to autonomic input}

It is widely accepted that the central nervous system via the autonomic projections regulates peripheral metabolism ${ }^{(90-92)}$. Such is the case of the SCN that coordinates peripheral circadian processes via humoral and autonomic output ${ }^{(93-97)}$. Nevertheless, if the autonomic pathway is in misbalance, negative consequences are observed ${ }^{(22,98-101)}$. For example, selective parasympathetic denervation to the adipose tissue decreases significantly the NEFA uptake $\mathrm{i}^{(102,103)}$ while liver parasympathectomy inhibits VLDL secretion ${ }^{(104)}$. In general, obesity and type 2 diabetes have been associated with increased sympathetic activity to heart, blood vessels, liver and adrenal glands ${ }^{(98,100,105)}$. It is suggested that this increased activity decreases the sensitivity of peripheral $\beta$-adrenergic receptors to autonomic input. This autonomic response seems to be impaired in peripheral tissues, since blood pressure remains high in type 2 diabetes and obesity conditions. So far there are no reports about how the autonomic system works in animals fed during their rest phase; however, we propose that one of the possible mechanisms that underlies the negative cost of food intake during the rest phase is by interfering with the neural communication pathway with the SCN. For example, in rodents, stimulating SCN with intense light to the eye during the rest-phase period induces hyperglycaemia via adrenergic pathways $^{(106)}$ and a light stimulus at night augments the expression of gluconeogenic genes via the autonomic system ${ }^{(107)}$. These parameters are coordinated by the $\mathrm{SCN}^{(108)}$; hence, when animals ingest their meal during the rest phase, the SCN has set the autonomic nervous system output to the 'rest period mode' and may promote increased lipid storage in the adipose tissue, and liver ${ }^{(109)}$ as well as a decreased insulin sensitivity and reduced energy expenditure.

\section{Melatonin}

Melatonin is a hormone synthesised and secreted during the night mainly by the pineal gland and it is associated with central processes associated with the dark period and enforcement of circadian rhythms by acting on the SCN as an internal synchroniser ${ }^{(110,111)}$. It influences insulin secretion and glucose uptake in rodents and melatonin supplemented in the drinking water is reported to reduce obesity and restore adipokine balance in ob/ob mice ${ }^{(112,113)}$. In mice the production of melatonin has been under debate; however, there is evidence that the pineal gland of different strains of mice (Balb7c, NOD) exhibits a nocturnal peak of melatonin ${ }^{(114)}$. Moreover, rats subjected to pinealectomy present glucose intolerance and basal hyperglycaemia ${ }^{(115)}$. Based on this knowledge, we propose that in rodents consuming their meal during the day, melatonin signalling is lacking and this may contribute to reduced insulin sensitivity, glucose is converted to fatty acids and latter to TAG; this may stimulate adipogenesis, as well as fatty liver if this condition persists. In spite of that in humans melatonin is released during the rest phase and thus out of phase with the eating cycle, there are numerous reports indicating that melatonin plays an important role in metabolic homeostasis by tuning insulin concentration in plasma ${ }^{(116)}$ and preventing obesity ${ }^{(117,118)}$. Another possible role is its chronobiotic effect on the circadian system by keeping circadian synchrony ${ }^{(119)}$.

\section{Missing answers: is gut microbiota responsible for the metabolic changes between day and night feeding?}

In the context of obesity, metabolic alterations commonly develop in a state of low-grade chronic inflammation that arises from impaired adipocyte function and contribute to ectopic fat accumulation and insulin resistance. While increased adiposity is consistent in resting-phase feeding studies, so far in those studies there is little or no evidence of changes in adipocyte function and/or inflammatory biomarkers, either systemic or in the adipose tissue. In addition, although glucose tolerance curves have been performed, it will be desirable to also assess hepatic insulin resistance to have more insight into the plausible mechanism.

One of the most common complaints of shift workers are gastrointestinal problems; indeed, there is evidence of a higher risk of colon cancer ${ }^{(4,120)}$. In addition, intestinal permeability and inflammation are associated with the development of hepatic steatosis ${ }^{(121,122)}$. To the best of our knowledge, none of the reports mentioned above has addressed the impact of food timing on intestinal physiology. Considering that various intestinal activities - such as gastrointestinal motility, gastric emptying, DNA synthesis, epithelial cell renewal, and nutrient and electrolyte absorption - occur in a circadian pattern ${ }^{(123)}$, it is possible that time of feeding could alter some of these processes and thus disturb intestinal physiology. It is worth noting that with a HF diet, gastrointestinal alterations may precede the onset of obesity and metabolic disturbances ${ }^{(124)}$. If we consider that the gastrointestinal tract is the largest endocrine organ, and has the second highest amount of immune cells in the body, we can speculate that a disruption in its rhythmic coordination might well influence the metabolic effects of the timing of food intake.

In the past 10 years the role of the gut microbiota in host metabolism and in the development of metabolic abnormalities has been demonstrated ${ }^{(125,126)}$. In the absence of gut microbiota, the circadian clock in intestinal epithelial cells was disrupted and mice developed metabolic disturbances ${ }^{(127)}$. It was recently demonstrated that intestinal microbiota composition and functionality also show a diurnal rhythmicity in rodents and in human subjects ${ }^{(60,128)}$ and that disruption of the host circadian clock by deletion of the core molecular clock gene, Bmal1, abolished this rhythmicity ${ }^{(129)}$. Feeding time also dictates daily oscillations in microbiota composition and circadian disruption, induced by jet lag, caused significant dysbiosis (microbiota imbalance), thus contributing to the development of metabolic disturbances. Voigt et al. ${ }^{(130)}$ also addressed the impact of circadian disruption (through continuing phase shifting) on the profile of gut microbiota, when animals were fed a HF diet (a 'challenging environment') and found a significant change in bacterial populations, supporting Thaiss's results ${ }^{(128)}$. Moreover, it was also shown that a HF diet partially abolished circadian fluctuations in gut microbiota composition ${ }^{(60)}$. These findings indicate that there is 


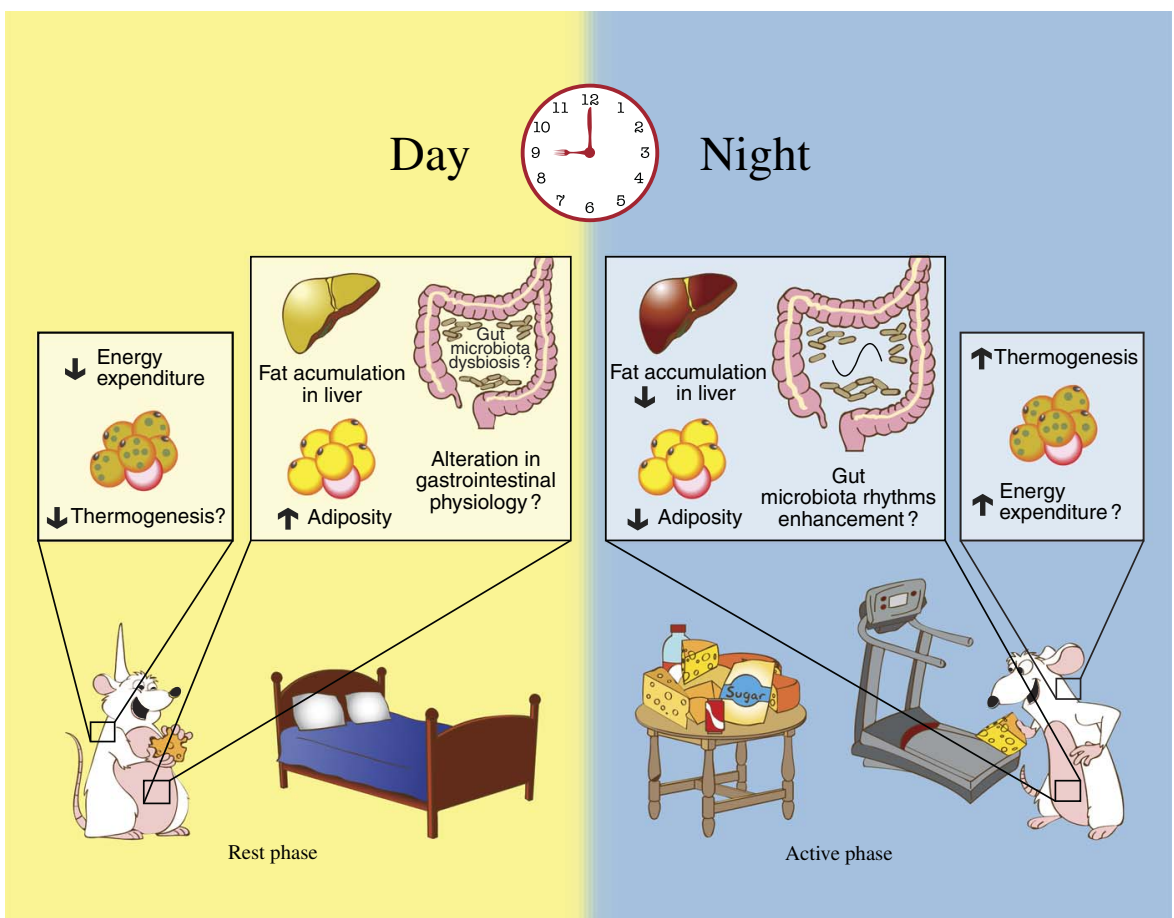

Fig. 1. Metabolic effects of eating during the active $v$. inactive phase. Eating during the inactive phase leads to greater adiposity, accumulation of fat in the liver, possibly related to lower energy expenditure and changes in gut microbiota and intestinal physiology. Eating at the correct time (active phase) prevents the adiposity and accumulation of fat in the liver, driven by high-fat diets. This effect is probably related to restoration of circadian fluctuations in gut microbiota composition and to an increase in energy expenditure. For a colour figure, see the online version.

a bidirectional communication between the circadian clock and microbiota, and therefore key to understand the influence of food timing on metabolic outcome. Indeed germ-free mice fed a low-fat or HF diet show altered circadian clock gene expression despite persistence of light-dark signals ${ }^{(131)}$.

There is a wide range of microbiota-derived metabolites that have been linked to the low-grade inflammation phenotype, fatty liver and $\mathrm{CVD}^{(125)}$. Indeed, it was recently shown that diurnal oscillations of microbial metabolites are altered with HF diets directly making an impact on circadian clock gene expression in the liver, leading to a lower metabolic state ${ }^{(131)}$, meaning that there is a lower use of substrates for energy production and more used for accumulation. So the research mentioned above might well be the tip of the iceberg, and further investigations of the type of microbiota, their metabolites, and its interaction with the clock system could possibly contribute to explain the metabolic alterations observed under different food timings. In time-restricted feeding studies only Zarrinpar et al. ${ }^{(60)}$ have evaluated the composition of the gut microbiota. Since the gut microbiota is deeply affected by environmental factors, some of the inconsistent findings among the studies here reviewed could also be due to differences in the gut microbiota functionality, that can largely vary due to different chow diets (non-purified diets) or even housing conditions in the vivarium.

\section{Conclusion and final perspectives}

Restricting food intake to the active phase (night in rodents) limits adiposity and metabolic disturbances such as hepatic steatosis and insulin resistance produced by high-energy diets. In contrast, eating during the inactive phase leads to greater adiposity, and in the long term to fat accumulation in the liver. The mechanisms are still not clear; while they could be related to decreased thermogenesis, the gut microbiota could provide possible mechanisms (Fig. 1).

Animal studies agree that within the active phase, breakfast is a 'better' time for food intake. This will limit the impact of HF diets, such as the typical Western diet. Breakfast eating is accompanied by an improved metabolic plasticity, to use fat as the energy substrate, which may contribute to the observed effect. So after all the ancient wisdom of 'Breakfast like a king, lunch as a prince, dine as a pauper' could hold also in animal studies some truth. This correlates with human studies, supporting the potential of animal studies to explore the mechanisms of human findings ${ }^{(8,56,79,132,133)}$. Nonetheless, wellcontrolled long-term experimental studies in animal models are needed to strengthen the animal experimental data and to further investigate metabolic variables such as adipocyte dysfunction and gut microbiota-host interactions that contribute to the development of obesity and metabolic disturbances.

\section{Acknowledgements}

The group is supported by Proyecto de Investigación e Innovación Tecnológica, Dirección General de Asuntos del Personal Académico-Universidad Nacional Autónoma de México (PAPIIT DGAPA-UNAM) project no. IG200314. S. M.-R. 
received a postdoctoral fellowship from DGAPA. DGAPAUNAM had no role in the design, analysis or writing of this article.

C. E. and S. M.-R. conducted the literature research and analysed the data; C. E., S. M.-R., R. B. and A. B.-R. wrote the paper, C. E. and S. M.-R. are primarily responsible for final content. All authors read and approved the final manuscript.

There are no conflicts of interest.

\section{References}

1. Ekmekcioglu C \& Touitou Y (2011) Chronobiological aspects of food intake and metabolism and their relevance on energy balance and weight regulation. Obes Rev 12, 14-25.

2. Garaulet M \& Madrid JA (2010) Chronobiological aspects of nutrition, metabolic syndrome and obesity. Adv Drug Deliv Rev 62, 967-978.

3. Haupt CM, Alte D, Dörr M, et al. (2008) The relation of exposure to shift work with atherosclerosis and myocardial infarction in a general population. Atherosclerosis 201, 205-211.

4. Knutsson A \& Bøggild H (2010) Gastrointestinal disorders among shift workers. Scand J Work Environ Health 36, $85-95$.

5. Canuto R, Garcez AS \& Olinto MTA (2012) Metabolic syndrome and shift work: a systematic review. Sleep Med Rev 17, 425-431.

6. Varady KA, Hoddy KK, Kroeger CM, et al. (2015) Determinants of weight loss success with alternate day fasting. Obes Res Clin Pract (epublication ahead of print version 15 September 2015).

7. Seimon RV, Roekenes JA, Zibellini J, et al. (2015) Do intermittent diets provide physiological benefits over continuous diets for weight loss? A systematic review of clinical trials. Mol Cell Endocrinol 418, 153-172.

8. Ma Y, Bertone ER, Stanek EJ, et al. (2003) Association between eating patterns and obesity in a free-living US adult population. Am J Epidemiol 158, 85-92.

9. Brookheart RT, Michel CI \& Schaffer JE (2009) As a matter of fat. Cell Metab 10, 9-12.

10. Després J-P \& Lemieux I (2006) Abdominal obesity and metabolic syndrome. Nature 444, 881-887.

11. Gregor MF \& Hotamisligil GS (2011) Inflammatory mechanisms in obesity. Annu Rev Immunol 29, 415-445.

12. McArdle MA, Finucane OM, Connaughton RM, et al. (2013) Mechanisms of obesity-induced inflammation and insulin resistance: insights into the emerging role of nutritional strategies. Front Endocrinol (Lausanne) 4, 52.

13. Golombek DA, Casiraghi LP, Agostino PV, et al. (2013) The times they're a-changing: effects of circadian desynchronization on physiology and disease. J Physiol Paris 107, 310-322.

14. Escobar C, Salgado R, Rodriguez K, et al. (2011) Scheduled meals and scheduled palatable snacks synchronize circadian rhythms: consequences for ingestive behavior. Physiol Behav 104, 555-561.

15. Perez-Mendoza M, Rivera-Zavala JB \& Diaz-Munoz M (2014) Daytime restricted feeding modifies the daily variations of liver gluconeogenesis: adaptations in biochemical and endocrine regulators. Chronobiol Int 31, 815-828.

16. Buijs RM, Escobar C \& Swaab DF (2013) The circadian system and the balance of the autonomic nervous system. Handb Clin Neurol 117, 173-191.

17. Oosterman JE, Kalsbeek A, Fleur SE, et al. (2014) Impact of nutrients on circadian rhythmicity. Am J Physiol Regul Integr Comp Physiol 308, R337-R350.
18. Buijs RM, Scheer FA, Kreier F, et al. (2006) Organization of circadian functions: interaction with the body. Prog Brain Res 153, 341-360.

19. Buijs FN, Cazarez F, Basualdo MC, et al. (2014) The suprachiasmatic nucleus is part of a neural feedback circuit adapting blood pressure response. Neuroscience 266, 197-207.

20. Hastings MH, Reddy AB \& Maywood ES (2003) A clockwork web: circadian timing in brain and periphery, in health and disease. Nat Rev Neurosci 4, 649-661.

21. Challet E (2013) Circadian clocks, food intake, and metabolism. Prog Mol Biol Transl Sci 119, 105-135.

22. Cailotto C, van Heijningen C, van der Vliet J, et al. (2008) Daily rhythms in metabolic liver enzymes and plasma glucose require a balance in the autonomic output to the liver. Endocrinology 149, 1914-1925.

23. Bass J \& Takahashi JS (2010) Circadian integration of metabolism and energetics. Science 330, 1349-1354.

24. Bailey SM, Udoh US \& Young ME (2014) Circadian regulation of metabolism. J Endocrinol 222, R75-R96.

25. Zvonic S, Ptitsyn AA, Conrad SA, et al. (2006) Characterization of peripheral circadian clocks in adipose tissues. Diabetes 55, 962-970.

26. Shostak A, Husse J \& Oster H (2013) Circadian regulation of adipose function. Adipocyte 2, 201-206.

27. Harfmann BD, Schroder EA \& Esser KA (2015) Circadian rhythms, the molecular clock, and skeletal muscle. J Biol Rhythms 30, 84-94.

28. McCarthy JJ, Andrews JL, McDearmon EL, et al. (2007) Identification of the circadian transcriptome in adult mouse skeletal muscle. Physiol Genomics 31, 86-95.

29. Dyar KA, Ciciliot S, Wright LE, et al. (2014) Muscle insulin sensitivity and glucose metabolism are controlled by the intrinsic muscle clock. Mol Metab 3, 29-41.

30. Balsalobre A, Brown SA, Marcacci L, et al. (2000) Resetting of circadian time in peripheral tissues by glucocorticoid signaling. Science 289, 2344-2347.

31. Balsalobre A, Damiola F \& Schibler U (1998) A serum shock induces circadian gene expression in mammalian tissue culture cells. Cell 93, 929-937.

32. Schibler U, Ripperger J \& Brown SA (2003) Peripheral circadian oscillators in mammals: time and food. J Biol Rhythms 18, 250-260.

33. Yoo S-H, Yamazaki S, Lowrey PL, et al. (2004) PERIOD2:: LUCIFERASE real-time reporting of circadian dynamics reveals persistent circadian oscillations in mouse peripheral tissues. Proc Natl Acad Sci U S A 101, 5339-5346.

34. Vollmers C \& Gill S (2009) Time of feeding and the intrinsic circadian clock drive rhythms in hepatic gene expression. Proc Natl Acad Sci US A 106, 21453-21458.

35. Panda S, Antoch MP, Miller BH, et al. (2002) Coordinated transcription of key pathways in the mouse by the circadian clock. Cell 109, 307-320.

36. Hodge BA, Wen Y, Riley LA, et al. (2015) The endogenous molecular clock orchestrates the temporal separation of substrate metabolism in skeletal muscle. Skelet Muscle 5, 17.

37. Ribas-Latre A \& Eckel-Mahan K (2016) Interdependence of nutrient metabolism and the circadian clock system: importance for metabolic health. Mol Metab 5, 133-152.

38. Damiola F, Le Minh N, Preitner N, et al. (2000) Restricted feeding uncouples circadian oscillators in peripheral tissues from the central pacemaker in the suprachiasmatic nucleus. Genes Dev 14, 2950-2961.

39. Stokkan K, Yamazaki S \& Tei H (2001) Entrainment of the circadian clock in the liver by feeding. Science 291, 490-492. 
40. Hatori M, Vollmers C, Zarrinpar A, et al. (2012) Time-restricted feeding without reducing caloric intake prevents metabolic diseases in mice fed a high-fat diet. Cell Metab 15, 848-860.

41. Eckel-Mahan K, Patel V \& De Mateo S (2013) Reprogramming of the circadian clock by nutritional challenge. Cell 155, 1464-1478.

42. Pendergast JS, Branecky KL, Yang W, et al. (2013) High-fat diet acutely affects circadian organisation and eating behavior. Eur I Neurosci 37, 1350-1356.

43. Chaix A, Zarrinpar A, Miu P, et al. (2014) Time-restricted feeding is a preventative and therapeutic intervention against diverse nutritional challenges. Cell Metab 20, 991-1005.

44. Kohsaka A, Laposky AD, Ramsey KM, et al. (2007) High-fat diet disrupts behavioral and molecular circadian rhythms in mice. Cell Metab 6, 414-421.

45. Green CB, Takahashi JS \& Bass J (2008) The meter of metabolism. Cell 134, 728-742.

46. Turek FW, Joshu C, Kohsaka A, et al. (2005) Obesity and metabolic syndrome in circadian clock mutant mice. Science 308, 1043-1045.

47. Lefta M, Campbell KS, Feng H, et al. (2012) Development of dilated cardiomyopathy in Bmal1-deficient mice. Am J Physiol Heart Circ Physiol 303, 475-485.

48. Kohsaka A, Das P, Hashimoto I, et al. (2014) The circadian clock maintains cardiac function by regulating mitochondrial metabolism in mice. PLOS ONE 9, e112811.

49. Marcheva B, Ramsey KM, Buhr ED, et al. (2010) Disruption of the clock components CLOCK and BMAL1 leads to hypoinsulinemia and diabetes. Nature 466, 627-631.

50. Maury E, Hong HK \& Bass J (2014) Circadian disruption in the pathogenesis of metabolic syndrome. Diabetes Metab 40, 338-346.

51. Tahara Y \& Shibata S (2016) Circadian rhythms of liver physiology and disease: experimental and clinical evidence. Nat Rev Gastroenterol Hepatol 13, 217-226.

52. Johnston JD, Scheer FA \& Turek FW (2016) Circadian rhythms, metabolism, and chrononutrition in rodents and humans. Adv Nutr 7, 399-406.

53. Yang G, Chen L, Grant GR, et al. (2016) Timing of expression of the core clock gene Bmal1 influences its effects on aging and survival. Sci Transl Med 8, 324ra16.

54. Proper KI, van de Langenberg D, Rodenburg W, et al. (2016) The relationship between shift work and metabolic risk factors: a systematic review of longitudinal studies. Am J Prev Med 50, e147-e157.

55. Wang F, Zhang L, Zhang Y, et al. (2014) Meta-analysis on night shift work and risk of metabolic syndrome. Obes Rev 15, 709-720.

56. Colles SL, Dixon JB \& O'Brien PE (2007) Night eating syndrome and nocturnal snacking: association with obesity, binge eating and psychological distress. Int J Obes (Lond) 31, 1722-1730.

57. Arble DM, Bass J, Laposky AD, et al. (2009) Circadian timing of food intake contributes to weight gain. Obesity (Silver Spring) 17, 2100-2102.

58. Salgado-Delgado R, Angeles-Castellanos M, Saderi N, et al. (2010) Food intake during the normal activity phase prevents obesity and circadian desynchrony in a rat model of night work. Endocrinology 151, 1019-1029.

59. Reznick J, Preston E, Wilks DL, et al. (2013) Altered feeding differentially regulates circadian rhythms and energy metabolism in liver and muscle of rats. Biochim Biophys Acta 1832, 228-238.

60. Zarrinpar A, Chaix A, Yooseph S, et al. (2014) Diet and feeding pattern affect the diurnal dynamics of the gut microbiome. Cell Metab 20, 1006-1017.
61. Morris M, Araujo I, Pohlman R, et al. (2012) Timing of fructose intake: an important regulator of adiposity. Clin Exp Pharmacol Physiol 39, 57-62

62. Bray GA (2012) Fructose and risk of cardiometabolic disease. Curr Atheroscler Rep 14, 570-578.

63. Rutledge A \& Adeli K (2007) Fructose and the metabolic syndrome: pathophysiology and molecular mechanisms. Nutr Rev 65, 13-23.

64. Jang H, Lee G, Kong J, et al. (2012) Feeding period restriction alters the expression of peripheral circadian rhythm genes without changing body weight in mice. PLOS ONE 7, e49993.

65. Shamsi NA, Salkeld MD, Rattanatray L, et al. (2014) Metabolic consequences of timed feeding in mice. Physiol Behav 128, 188-201.

66. Tsai J, Villegas-Montoya C, Boland BB, et al. (2013) Influence of dark phase restricted high fat feeding on myocardial adaptation in mice. J Mol Cell Cardiol 55, 147-155.

67. Ussar S, Griffin NW, Bezy O, et al. (2015) Interactions between gut microbiota, host genetics and diet modulate the predisposition to obesity and metabolic syndrome. Cell Metab 22, 516-530.

68. Seale P \& Lazar MA (2009) Brown fat in humans: turning up the heat on obesity. Diabetes 58, 1482-1484.

69. Satoh Y, Kawai H, Kudo N, et al. (2006) Time-restricted feeding entrains daily rhythms of energy metabolism in mice. Am J Physiol Regul Integr Comp Physiol 290, R1276-R1283.

70. Borén J, Taskinen MR, Olofsson SO, et al. (2013) Ectopic lipid storage and insulin resistance: a harmful relationship. J Intern Med 274, 25-40.

71. Salgado-Delgado RC, Saderi N, Basualdo MDC, et al. (2013) Shift work or food intake during the rest phase promotes metabolic disruption and desynchrony of liver genes in male rats. PLOS ONE 8, e60052.

72. Adamovich Y, Rousso-Noori L, Zwighaft Z, et al. (2014) Circadian clocks and feeding time regulate the oscillations and levels of hepatic triglycerides. Cell Metab 19, 319-330.

73. Kalsbeek A, la Fleur S \& Fliers E (2014) Circadian control of glucose metabolism. Mol Metab 3, 372-383.

74. Shi SQ, Ansari TS, McGuinness OP, et al. (2013) Circadian disruption leads to insulin resistance and obesity. Curr Biol 23, 372-381.

75. Gil-Lozano M, Mingomataj EL, Wu WK, et al. (2014) Circadian secretion of the intestinal hormone, glucagon-like peptide-1, by the rodent L-cell. Diabetes 63, 3674-3685.

76. Tsai J-Y, Kienesberger PC, Pulinilkunnil T, et al. (2010) Direct regulation of myocardial triglyceride metabolism by the cardiomyocyte circadian clock. J Biol Chem 285, 2918-2929.

77. Wu T, Sun L, ZhuGe F, et al. (2011) Differential roles of breakfast and supper in rats of a daily three-meal schedule upon circadian regulation and physiology. Chronobiol Int 28, 890-903.

78. Apolzan JW \& Harris R (2012) Differential effects of chow and purified diet on the consumption of sucrose solution and lard and the development of obesity. Physiol Behav 105, 325-331.

79. Garaulet M, Gomez-Abellan $\mathrm{P}$, Alburquerque-Bejar J, et al. (2013) Timing of food intake predicts weight loss effectiveness. Int J Obes 37, 604-611.

80. Bray MS, Tsai J-Y, Villegas-Montoya C, et al. (2010) Time-ofday-dependent dietary fat consumption influences multiple cardiometabolic syndrome parameters in mice. Int $J$ Obes 34, 1589-1598. 
81. Sasaki H, Ohtsu T, Ikeda Y, et al. (2014) Combination of meal and exercise timing with a high-fat diet influences energy expenditure and obesity in mice. Chronobiol Int 31, 959-975.

82. Fuse Y, Hirao A, Kuroda H, et al. (2012) Differential roles of breakfast only (one meal per day) and a bigger breakfast with a small dinner (two meals per day) in mice fed a highfat diet with regard to induced obesity and lipid metabolism. J Circadian Rhythms 10, 4.

83. Aas V, Hessvik NP, Wettergreen M, et al. (2011) Chronic hyperglycemia reduces substrate oxidation and impairs metabolic switching of human myotubes. Biochim Biophys Acta 1812, 94-105.

84. Stanford KI, Middelbeek RJ, Townsend KL, et al. (2013) Brown adipose tissue regulates glucose homeostasis and insulin sensitivity. J Clin Invest 123, 215-223.

85. Townsend KL \& Tseng Y-H (2014) Brown fat fuel utilization and thermogenesis. Trends Endocrinol Metab 25, 168-177.

86. Dulloo AG (2006) Regulation of fat storage via suppressed thermogenesis: a thrifty phenotype that predisposes individuals with catch-up growth to insulin resistance and obesity. Horm Res 65, Suppl. 3, 90-97.

87. Yoneshiro T \& Aita S (2013) Recruited brown adipose tissue as an antiobesity agent in humans. J Clin Invest 123, 3404-3408.

88. Yoon J, Han D, Noh J, et al. (2012) Meal time shift disturbs circadian rhythmicity along with metabolic and behavioral alterations in mice. PLOS ONE 7, e44053.

89. Summermatter S, Marcelino H, Arsenijevic D, et al. (2009) Relevance for muscle-adipose glucose redistribution during catch-up growth. Diabetes 58, 2228-2237.

90. Buijs RM \& Kalsbeek A (2001) Hypothalamic integration of central and peripheral clocks. Nat Rev Neurosci 2, 521-526.

91. Myers MG \& Olson DP (2012) Central nervous system control of metabolism. Nature 491, 357-363.

92. Geerling JJ, Boon MR, Kooijman S, et al. (2014) Sympathetic nervous system control of triglyceride metabolism: novel concepts derived from recent studies. J Lipid Res 55, 180-189.

93. Kalsbeek A \& Buijs RM (2002) Output pathways of the mammalian suprachiasmatic nucleus: coding circadian time by transmitter selection and specific targeting. Cell Tissue Res 309, 109-118.

94. Buijs RM, van Eden CG, Goncharuk VD, et al. (2003) The biological clock tunes the organs of the body: timing by hormones and the autonomic nervous system. J Endocrinol 177, 17-26

95. Buijs RM, la Fleur SE, Wortel J, et al. (2003) The suprachiasmatic nucleus balances sympathetic and parasympathetic output to peripheral organs through separate preautonomic neurons. J Comp Neurol 464, 36-48.

96. Perreau-Lenz S, Pévet P, Buijs RM, et al. (2004) The biological clock: the bodyguard of temporal homeostasis. Chronobiol Int 21, 1-25.

97. Kalsbeek A, Palm IF, La Fleur SE, et al. (2006) SCN outputs and the hypothalamic balance of life. J Biol Rhythms 21, 458-469.

98. Kreier F, Yilmaz A, Kalsbeek A, et al. (2003) Hypothesis: shifting the equilibrium from activity to food leads to autonomic unbalance and the metabolic syndrome. Diabetes $\mathbf{5 2}$, 2652-2666.

99. Buijs RM \& Kreier F (2006) The metabolic syndrome: a brain disease? Neuroendocrinology 18, 715-716.

100. Tentolouris N, Argyrakopoulou G \& Katsilambros N (2008) Perturbed autonomic nervous system function in metabolic syndrome. Neuromolecular Med 10, 169-178.
101. Licht CMM, de Geus EJC \& Penninx BWJH (2013) Dysregulation of the autonomic nervous system predicts the development of the metabolic syndrome. J Clin Endocrinol Metab 98, 2484-2493.

102. Kreier F, Fliers E, Voshol PJ, et al. (2002) Selective parasympathetic innervation of subcutaneous and intraabdominal fat - functional implications. J Clin Invest 110, 1243-1250.

103. Fliers E, Kreier F, Voshol PJ, et al. (2003) White adipose tissue: getting nervous. J Neuroendocrinol 15, 1005-1010.

104. Bruinstroop E, Fleur SE, Ackermans MT, et al. (2013) The autonomic nervous system regulates postprandial hepatic lipid metabolism. Am J Physiol Endocrinol Metab 304, E1089-E1096.

105. Lips MA, de Groot GH, De Kam M, et al. (2013) Autonomic nervous system activity in diabetic and healthy obese female subjects and the effect of distinct weight loss strategies. Eur J Endocrinol 169, 383-390.

106. Niijima A, Nagai K, Nagai N, et al. (1993) Effects of light stimulation on the activity of the autonomic nerves in anesthetized rats. Physiol Behav 54, 555-561.

107. Cailotto C, Lei J, van der Vliet J, et al. (2009) Effects of nocturnal light on (clock) gene expression in peripheral organs: a role for the autonomic innervation of the liver. PLOS ONE $\mathbf{4}$, e5650.

108. Mutoh T, Shibata S, Korf H-W, et al. (2003) Melatonin modulates the light-induced sympathoexcitation and vagal suppression with participation of the suprachiasmatic nucleus in mice. $J$ Physiol 547, 317-332.

109. Sabath E, Baez-Ruiz A \& Buijs RM (2015) Non-alcoholic fatty liver disease as a consequence of autonomic imbalance and circadian desynchronization. Obes Rev 16, 871-882.

110. Pevet P \& Challet E (2011) Melatonin: both master clock output and internal time-giver in the circadian clocks network. J Physiol Paris 105, 170-182.

111. Agez L, Laurent V, Guerrero HY, et al. (2009) Endogenous melatonin provides an effective circadian message to both the suprachiasmatic nuclei and the pars tuberalis of the rat. J Pineal Res 46, 95-105.

112. Favero G, Stacchiotti A, Castrezzati S, et al. (2015) Melatonin reduces obesity and restores adipokine patterns and metabolism in obese (ob/ob) mice. Nutr Res 35, 891-900.

113. Mühlbauer E, Gross E, Labucay K, et al. (2009) Loss of melatonin signalling and its impact on circadian rhythms in mouse organs regulating blood glucose. Eur J Pharmacol 606, 61-71.

114. Conti A \& Maestroni GJ (1998) Melatonin rhythms in mice: role in autoimmune and lymphoproliferative diseases. Ann New York Acad Sci 840, 395-410.

115. Nogueira TC, Lellis-Santos C, Jesus DS, et al. (2011) Absence of melatonin induces night-time hepatic insulin resistance and increased gluconeogenesis due to stimulation of nocturnal unfolded protein response. Endocrinology 152, 1253-1263.

116. Lardone PJ, Alvarez-Sanchez SN, Guerrero JM, et al. (2014) Melatonin and glucose metabolism: clinical relevance. Curr Pharm Des 20, 4841-4853.

117. Szewczyk-Golec K, Wozniak A \& Reiter RJ (2015) Interrelationships of the chronobiotic, melatonin, with leptin and adiponectin: implications for obesity. J Pineal Res 59, $277-291$.

118. Cipolla-Neto J, Amaral FG, Afeche S, et al. (2014) Melatonin, energy metabolism, and obesity: a review. J Pineal Res 56, 371-381.

119. Pévet P (2014) The internal time-giver role of melatonin. A key for our health. Rev Neurol (Paris) 170, 646-652. 
120. Nojkov B, Rubenstein JH, Chey WD, et al. (2010) The impact of rotating shift work on the prevalence of irritable bowel syndrome in nurses. Am J Gastroenterol 105, 842-847.

121. Miele L, Valenza V, La Torre G, et al. (2009) Increased intestinal permeability and tight junction alterations in nonalcoholic fatty liver disease. Hepatology 49, 1877-1887.

122. Brun P, Castagliuolo I, Di Leo V, et al. (2007) Increased intestinal permeability in obese mice: new evidence in the pathogenesis of nonalcoholic steatohepatitis. Am J Physiol Gastrointest Liver Physiol 292, 518-525.

123. Hussain MM (2014) Regulation of intestinal lipid absorption by clock genes. Annu Rev Nutr 34, 357-375.

124. Ding S, Chi MM, Scull BP, et al. (2010) High-fat diet: bacteria interactions promote intestinal inflammation which precedes and correlates with obesity and insulin resistance in mouse. PLOS ONE 5, e12191.

125. Nicholson JK, Holmes E, Kinross J, et al. (2012) Host-gut microbiota metabolic interactions. Science 336, 1262-1267.

126. Schnabl B \& Brenner DA (2014) Interactions between the intestinal microbiome and liver diseases. Gastroenterology 146, 1513-1524.
127. Mukherji A, Kobiita A, Ye T, et al. (2013) Homeostasis in intestinal epithelium is orchestrated by the circadian clock and microbiota cues transduced by TLRs. Cell 153, 812-827.

128. Thaiss CA, Zeevi D, Levy M, et al. (2014) Transkingdom control of microbiota diurnal oscillations promotes metabolic homeostasis. Cell 159, 514-529.

129. Liang X, Bushman FD \& Fitzgerald GA (2015) Rhythmicity of the intestinal microbiota is regulated by gender and the host circadian clock. Proc Natl Acad Sci U S A 112, 10479-10484.

130. Voigt RM, Forsyth CB, Green SJ, et al. (2014) Circadian disorganization alters intestinal microbiota. PLOS ONE 9, e97500.

131. Leone V, Gibbons SM, Martinez K, et al. (2015) Effects of diurnal variation of gut microbes and high-fat feeding on host circadian clock function and metabolism. Cell Host Microbe 17, 681-689.

132. Allison KC, Goel N \& Ahima RS (2014) Delayed timing of eating: impact on weight and metabolism. Curr Obes Rep 3, 91-100.

133. Jakubowicz D, Barnea M, Wainstein J, et al. (2013) High caloric intake at breakfast vs. dinner differentially influences weight loss of overweight and obese women. Obesity $\mathbf{2 1}$, 2504-2512. 